Article

\title{
Sorption and Desorption Analysis of Nitrobenzene on Differently Functionalized Multiwalled Carbon Nanotubes and Implications on the Stability
}

\author{
Zhanhua Ji ${ }^{1,2}$ and Dengyu Li ${ }^{1, *}$ \\ 1 Key Laboratory of Pollution Ecology and Environmental Engineering, Institute of Applied Ecology, \\ Chinese Academy of Sciences, Shenyang 110016, China; jizhanhua12@mails.ucas.ac.cn \\ 2 College of Resources and Environment, University of Chinese Academy of Sciences, Beijing 100049, China \\ * Correspondence: lidengyu@iae.ac.cn
}

Citation: Ji, Z.; Li, D. Sorption and Desorption Analysis of Nitrobenzene on Differently Functionalized Multiwalled Carbon Nanotubes and Implications on the Stability. Water 2021, 13, 1426. https://doi.org/ $10.3390 /$ w13101426

Academic Editor: José Alberto Herrera-Melián

Received: 22 April 2021

Accepted: 17 May 2021

Published: 20 May 2021

Publisher's Note: MDPI stays neutral with regard to jurisdictional claims in published maps and institutional affiliations.

Copyright: (c) 2021 by the authors. Licensee MDPI, Basel, Switzerland. This article is an open access article distributed under the terms and conditions of the Creative Commons Attribution (CC BY) license (https:// creativecommons.org/licenses/by/ $4.0 /)$.

\begin{abstract}
The stability of carbon nanotubes (CNTs) suspension is a key factor in determining their transport, fate, and toxicity in an aquatic environment, which is significantly influenced by CNTs' nature and water chemistry. Macromolecular dissolved organic matter (DOM) is reported to influence the stability of CNTs aggregation. However, little is known on small polar dissolved organic compound's effects on CNTs aggregation. Nitrobenzene was selected to investigate its interaction with three different functionalized multiwalled CNTs (MWCNTs). Both the stability of CNTs aggregation and sorption hysteresis were affected by the initial concentration of nitrobenzene and the surface functionalization coverage of MWCNTs. At the initial concentration below $580 \mathrm{mg} / \mathrm{L}$, the thermodynamic index of irreversibility (TII) and turbidity of CNTs suspension had the same tendency, indicating that the underlying mechanism is closely related. A conceptual adsorption-desorption model was proposed to further explain the relationship between the sorption hysteresis and stability of MWCNTs suspension under different initial concentrations of nitrobenzene. This provided data support to further clarify the environmental behaviors and risks of CNTs.
\end{abstract}

Keywords: stability of aggregation; sorption and desorption; sorption hysteresis; nitrobenzene; multiwalled carbon nanotubes (MWCNTs)

\section{Introduction}

Carbon nanotubes (CNTs) are gaining increasingly more attention since their first discovery in 1991 [1]. Due to their unique and tunable properties, CNTs have many potential applications-electrochemical capacitors, catalyst supports, optical devices, membrane distillation, biomedical use, and absorbents in contaminated water treatment [2-6]. CNTrelated commercial activity grew most substantially in the past decade. For example, in 2011 alone, the CNTs production capacity was estimated to exceed 4500 tons [3]. CNTs are insoluble in water and slightly biodegradable; inhibit seed germination and root growth; specifically target organ toxicity to spermatogonia and oocytes; and are mutagenic to aquatic organisms by damaging DNA [7-9]. Once released into the aquatic environment, CNTs inevitably interact with the co-existing media in water. Due to their strong hydrophobicity and high specific surface area, CNTs concentrate pollutants in water, especially organic pollutants, and enter the food chain together, through the ingestion of floating organisms, thus, posing potential threats to the environment and human health [10]. On the one hand, adsorption and desorption of organic compounds molecules by CNTs can affect the transport and bioavailability of organic compounds in water. On the other, organic molecules like dissolved organic matter and surfactants, can help enhance the stability of CNTs suspension in aqueous solution, and consequently affect the aggregation behavior of CNTs [11]. This can also affect the cloudiness or haziness (turbidity) of CNTs suspension. Changes in size and diffusion efficiency and surface structure caused by aggregation behavior, directly affect the migration behavior (such as, outward migration distance (in $\mathrm{m}$ or 
$\mathrm{km}$ ) from source of pollution) and the bioavailability of CNTs in water, and change their reactivity and toxicological properties in water $[9,10]$. The changes also affect the efficacy of absorption and reusability cycles when used as sorbents in the treatment of polluted water, which determine the removal rate of pollutants and cost of wastewater treatment [5]. These are related to the safety of natural water and the quality of wastewater treatment. Therefore, it is of great importance to study the sorption and desorption mechanisms of organic compounds by CNTs in aqueous phases.

There are many studies on adsorption of polycyclic aromatic hydrocarbons [12], antibacterial agents [13], endocrine disrupting chemicals [14], natural organic matter [15], heavy metals [16], and proteins [17] by CNTs. Among those studies, much attention is focused on the factors controlling the magnitude of sorption by CNTs in single step uptake experiments, while little attention is paid to the sorption hysteresis, by including the desorption steps. As sorption hysteresis can have important implications for both modeling the pollutant behavior and understanding the mechanism of sorption and desorption, it is feasible to explain the stability of CNTs by inferring the mechanism of the change of CNTs during the adsorption process, based on the sorption hysteresis phenomenon [18].

There are two types of sorption hysteresis-reversible and irreversible hysteresis. Irreversible hysteresis is the non-coincidence of the sorption and desorption branches of the experimental isotherm [19], which manifests as enhanced affinity of the sorbate for the solid, in a dilution step or repeat step [20-26]. It has two types-artificial and true. Two mechanisms were proposed to explain the true irreversible hysteresis [25]. (i) The formation of metastable states of adsorbate in fixed mesopores (i.e., capillary condensation hysteresis) and (ii) pore deformation. Pore deformation would occur when the deformed pore structure did not recover to its original state during desorption [27]. Both reversible and irreversible hysteresis was observed in organic compounds' sorption and desorption by CNTs. Reversible hysteresis was observed for the non-polar organic compounds [23], while irreversible hysteresis was found for the polar compounds [13,14]. Zhao et al. reported that the molecules with a small charge transfer and weak binding did not cause any change of single-wall CNTs (SWCNTs) electronic properties after adsorption, but for molecules with considerable charge transfer and strong adsorption, both electronic band structures and density of state significantly changed after adsorption [28]. Hence, the opposite hysteresis found in non-polar and polar organic compounds might be attributed to the polar group of organic compounds, which consequently causes the rearrangement of CNTs aggregates [14]. However, how the polar group affects CNTs aggregates remains unknown. Natural organic matter and surfactants are widely used as dispersants to yield stable CNTs dispersions, because they contain sufficient hydrophobic regions and provide steric or electrostatic repulsions during adsorbing to and wrapping around the exterior of CNTs $[15,29]$. Since solutions of small molecular organic compounds in some aspects can be regarded as dissolved organic matter, we speculated that small molecular organic compounds, especially polar organic compounds, can to some extent affect the stability of CNTs suspension.

The present study was designed to clarify the relationship between the sorptiondesorption mechanism of small polar organic compounds by CNTs and the stability of CNTs. Three different functionalized multi-walled CNTs (MWCNTs) were selected as sorbents. In addition to the one-dimensional space tube structure, MWCNTs also have multilayer interlaminar pore walls and abundant mesopores that are conducive to the diffusion of reactants on the surface of adsorbents in aqueous solutions. MWCNTs are the most cost-effective, so they are often selected as sorbents for wastewater treatment. [30,31]. Nitrobenzene was chosen to represent small polar organic compounds, as it is among the priority pollutant mainly in oil refinery wastewaters and is often detected in natural water environment $[32,33]$. Our objectives, therefore, were (i) to study the sorption and desorption mechanisms, namely, the sorption hysteresis of nitrobenzene on MWCNTs; (ii) to test whether or not nitrobenzene will affect the stability of MWCNTs suspension, and (iii) to assess how the stability of MWCNTs suspension will affect the sorption hysteresis. 


\section{Materials and Methods}

\subsection{Materials}

Nitrobenzene was purchased from Acros Organics Co. The molecular weight (MW), water solubility $\left(25^{\circ} \mathrm{C}\right)$ and density of nitrobenzene was $123.11 \mathrm{~g} / \mathrm{mol}, 1820 \mathrm{mg} / \mathrm{L}$, and $1.199 \mathrm{~g} / \mathrm{cm}^{3}$, respectively. The MWCNTs used in this study, including graphitized ( $\mathrm{G}-\mathrm{CNTs})$, hydroxylized ( $\mathrm{H}-\mathrm{CNTs})$, and carboxylized (C-CNTs), were purchased from Chengdu Organic Chemistry Co., Chengdu, China, Chinese Academy of Sciences and used without further treatment. On the basis of the information provided by the manufacturer, these CNTs were synthesized in the $\mathrm{CH}_{4} / \mathrm{H}_{2}$ mixture by the chemical vapor deposition at $700{ }^{\circ} \mathrm{C}$. G-CNTs were made by CNTs under inert gas at $2800^{\circ} \mathrm{C}$. $\mathrm{H}-\mathrm{CNTs}$ were produced by CNTs with $\mathrm{KMnO}_{4}$ oxidation in $\mathrm{H}_{2} \mathrm{SO}_{4}$ solution. $\mathrm{C}-\mathrm{CNTs}$ were generated from $\mathrm{CNTs}$ with $\mathrm{KMnO}_{4}$ oxidation in $\mathrm{NaOH}$ solution $[34,35]$. The chemical structure sketches are shown in Figure S1 (Supplementary Materials). Selected physicochemical properties are listed in Table S1 (Supplementary Materials).

\subsection{Sorption-Desorption Experiments}

Sorption experiments of MWCNTs were performed using a batch equilibration technique at $25 \pm 1{ }^{\circ} \mathrm{C}$. In brief, $50 \mathrm{mg}$ functionalized MWCNTs were added into $8 \mathrm{~mL}$ background solutions $\left(0.01 \mathrm{~mol} / \mathrm{L} \mathrm{CaCl}_{2}\right.$ and $200 \mathrm{mg} / \mathrm{L} \mathrm{NaN}_{3}$ in deionized distilled water, $\mathrm{pH}=7)$ with different initial concentrations $\left(C_{0}\right)$ of nitrobenzene range from $5.06 \mathrm{mg} / \mathrm{L}$ to $1324.5 \mathrm{mg} / \mathrm{L}$. The mixture was kept in an $8 \mathrm{~mL}$ Teflon-lined screw cap glass vial. The vials were placed on a rotary shaker in the dark for $72 \mathrm{~h}$ at $150 \mathrm{rpm}$, under $25 \pm 1^{\circ} \mathrm{C}$. Preliminary experiments showed that adsorption of nitrobenzene on the three MWCNTs reached equilibrium in $72 \mathrm{~h}$. After centrifugation ( $3000 \mathrm{rpm}$, namely, $1237 \times g$ for $20 \mathrm{~min}$ ), the concentration of nitrobenzene in the supernatant was determined by an Agilent $8453 \mathrm{UV}$ spectrophotometer, at the maximum adsorption wavelength of $268 \mathrm{~nm}$. The total loss of nitrobenzene in vials without MWCNTs was less than $2 \%$ of the initial concentrations. It showed that there was little sorption by vials, no biodegradation, and less experimental uncertainty. Thus, the adsorbed nitrobenzene by MWCNTs was calculated by the mass difference between the initial and equilibrium concentrations. Desorption experiment was arranged immediately after sorption $[13,14,27]$. A total of $4 \mathrm{~mL}$ of supernatant was removed from the vials and the same volume of background solution was added. The vials were then shaken continuously for another $72 \mathrm{~h}$. After $72 \mathrm{~h}$, the vials were centrifuged and the new equilibrium concentration in the supernatant was determined. The procedures of desorption experiments were repeated for the second and the third desorption cycles.

\subsection{Stabilization Experiments}

The stability of MWCNTs in the aqueous phase were determined and compared by the UV absorption value at $800 \mathrm{~nm}$ (Agilent $8453 \mathrm{UV}$ spectrophotometer) [36,37]. In brief, $50 \mathrm{mg}$ functionalized MWCNTs and $8 \mathrm{~mL}$ background solutions containing different nitrobenzene concentrations were mixed in $8 \mathrm{~mL}$ glass vials. The vials were sealed with Teflon-lined screw caps and shaken in the dark for $72 \mathrm{~h}$. After 5 minutes' settling, the absorbance at $800 \mathrm{~nm}$ in solution was determined. The reason why we selected $5 \mathrm{~min}$ was because, after an hour, the CNTs in solution either reach the top or settle down at the bottom (Figure S4 in Supplementary Materials).

\subsection{Data Analysis}

\subsubsection{Sorption Isotherm Fitting}

Four different models were used in this study. The equations are listed as follows: Langmuir model (LM):

$$
q_{e}=Q^{0} b C_{e} /\left(1+b C_{e}\right)
$$


where $q_{e}(\mathrm{mg} / \mathrm{g})$ is the equilibrium sorbed concentration. $C_{e}(\mathrm{mg} / \mathrm{L})$ is the equilibrium solution phase concentration; $Q^{0}(\mathrm{mg} / \mathrm{g})$ is the maximum monolayer adsorption capacity; and $b$ is a constant related to the molar heat of adsorption.

Freundlich model (FM):

$$
q_{e}=k_{f} C_{e}^{n}
$$

where $K_{f}\left((\mathrm{mg} / \mathrm{g}) /(\mathrm{mg} / \mathrm{L})^{1 / n}\right)$ is the Freundlich affinity coefficient. $n$ is the Freundlich exponential coefficient.

Dual-mode model (DMM):

$$
q_{e}=Q^{0} b C_{e} /\left(1+b C_{e}\right)+K_{d} C_{e}
$$

where $Q^{0}(\mathrm{mg} / \mathrm{g})$ is the saturated sorbed capacity; $K_{d}(\mathrm{~L} / \mathrm{g})$ is the partition coefficient; and $b$ is the affinity constants.

Polanyi-Manes model (PMM):

$$
\log q_{e}=\log Q^{0}+a\left(\varepsilon / V_{s}\right)^{b}
$$

where $Q^{0}(\mathrm{mg} / \mathrm{g})$ is the saturated sorbed capacity; $\varepsilon(\mathrm{kJ} / \mathrm{mol})=\mathrm{RT} \ln \left(C_{s} / C_{e}\right)$ is the effective adsorption potential; $\mathrm{R}\left(8.314 \times 10^{-3} \mathrm{~kJ} /(\mathrm{mol} \cdot \mathrm{K})\right)$ is the universal gas constant; $\mathrm{T}(\mathrm{K})$ is the absolute temperature; $V_{S}\left(\mathrm{~cm}^{3} / \mathrm{mol}\right)=\mathrm{MW}(\mathrm{g} / \mathrm{mol}) /$ density $\left(\mathrm{g} / \mathrm{cm}^{3}\right)$ is the molar volume of nitrobenzene; and $b$ is the fitting parameter.

\subsubsection{Thermodynamic Index of Irreversibility}

Thermodynamic index of irreversibility (TII) is a useful tool for quantifying hysteresis, which facilitates the understanding of the mechanisms of sorption hysteresis [25]. In this study, a Freundlich form of TII was adopted [13,25]:

$$
T I I_{\text {Freundlich }}=1-n_{\text {desorb }} / n_{\text {sorb }}
$$

where $n_{\text {desorb }}$ and $n_{\text {sorb }}$ are the nonlinear factors for desorption and sorption isotherms, respectively.

\section{Results}

\subsection{Characterization of Carbon Nanotubes}

Although the three functionalized MWCNTs produced by different treatments had similar length and size (such as, outer diameter, inner diameter, and average pore diameter), their oxygen element distributions were different (Table S1 in Supplementary Materials). Compared to $\mathrm{G}-\mathrm{CNTs}, \mathrm{H}-\mathrm{CNTs}$ and $\mathrm{C}-\mathrm{CNTs}$ had a higher total oxygen content $(2.9 \%$ and $0.5 \%$, respectively) and more functionalized surface carbon $(4.28 \%$ and $2.19 \%$, respectively). These were caused by the hydroxyl group and the carboxylic acid group formed by oxidation. Different total oxygen but similar surface oxygen content ( $4.1 \%$ and $4.2 \%$, respectively) of $\mathrm{H}-\mathrm{CNTs}$ and $\mathrm{C}-\mathrm{CNTs}$ also implied that they might had different inner nanopores, which were demonstrated by the different porous properties among the three materials. Moreover, the special surface area, micropore surface area, mesopore surface area, total pore volume, micropore volume, and the mesopore volume of three functionalized MWCNTs, all followed the order: $\mathrm{H}-\mathrm{CNTs}>\mathrm{C}-\mathrm{CNTs}>\mathrm{G}-\mathrm{CNTs}$. Thus, the surface functionalization coverage of CNTs had changed the structure, especially the surface area and porosity of CNTs that might provide different adsorption and binding sites [12].

\subsection{Sorption Isotherms Modeling}

Sorption isotherms of nitrobenzene by three functionalized MWCNTs are shown in Figure S3 (Supplementary Materials). All sorption isotherms can be divided into two stages - a Langmuir type followed by a linear. In general, for a given equilibrium concentration, the amount of sorbed nitrobenzene on CNTs followed the order: $\mathrm{H}-\mathrm{CNTs}$ 
$>\mathrm{C}-\mathrm{CNTs}>\mathrm{G}-\mathrm{CNTs}$, which was consistent with the CNTs surface area (for example, special surface area, $159.4>145.5>133.6$ ) and the pore volume (for example, total pore volume, $0.310>0.280>0.257$ ). Nonlinearity was observed for all isotherms. Therefore, nonlinear isotherm models (Table 1), i.e., LM, FM, DMM, and PMM models were applied to fit the experimental data. The relatively high $Q^{0}$ value in Table 1 and relatively fast adsorption equilibrium in the preliminary experiments indicated that CNTs could be used as good sorbents for the treatment of nitrobenzene wastewater $[6,11]$.

Compared to the fitting adjusted square of the correlation coefficient $\left(r_{a d j}{ }^{2}\right)$, the DMM, PMM, and FM models showed a better fit than LM. The DMM model was first proposed for describing the sorption behavior of sorbents that contained both partition and adsorption domain [38]. The CNTs did not have any amorphous carbon. However, DMM could also be applied to the two-stage sorption process, by first assuming the interaction between sorbate and sorbents followed by the polar interactions between sorbents and free sorbate molecules [36]. The PMM model is based on the assumption that there exists an attractive force field (i.e., adsorption space) on the sorbent surface and adsorption potential for any adsorbate molecule is dependent on the distance between the molecule and the solid surface [12]. The FM model can be regarded as a special form of PPM model when $b=1$ [12]. Overall, the adsorption process of nitrobenzene onto three MWCNTs would be neither monolayer formation on a homogeneous surface nor a simple multilayer formation. Some physical and chemical reactions might be involved in the adsorption process, which might affect the conformation of CNTs $[13,15]$. Therefore, which model is better fit for sorption of nitrobenzene by CNTs depends on whether the bilayer adsorption or staged adsorption occurs or not.

Table 1. Results of sorption models of nitrobenzene by the functionalized CNTs.

\begin{tabular}{|c|c|c|c|c|c|c|c|}
\hline \multicolumn{8}{|c|}{ Sorption Isotherms Parameters Fitted by Four Models ${ }^{1}$} \\
\hline \multicolumn{8}{|c|}{ Langmuir model (LM) } \\
\hline CNTs & $Q^{0}$ & $P$ of $Q^{0}$ & $b$ & $\mathrm{P}$ of $b$ & - & - & $r_{a d j}^{2}$ \\
\hline $\mathrm{G}-\mathrm{CNTs}$ & $38.9 \pm 1.7$ & $<0.0001$ & $0.0078 \pm 0.0013$ & $<0.0001$ & - & - & 0.971 \\
\hline $\mathrm{H}-\mathrm{CNTs}$ & $42.6 \pm 2.3$ & $<0.0001$ & $0.0070 \pm 0.0013$ & $<0.0001$ & - & - & 0.964 \\
\hline $\mathrm{C}-\mathrm{CNTs}$ & $42.6 \pm 2.9$ & $<0.0001$ & $0.0052 \pm 0.0010$ & $<0.0001$ & - & - & 0.961 \\
\hline \multicolumn{8}{|c|}{ Freundlich model (FM) } \\
\hline CNTs & $K_{f}$ & $\mathrm{P}$ of $K_{f}$ & $n$ & P of $n$ & - & - & $r_{a d j}{ }^{2}$ \\
\hline $\mathrm{G}-\mathrm{CNTs}$ & $2.20 \pm 0.20$ & $<0.0001$ & $0.413 \pm 0.014$ & $<0.0001$ & - & - & 0.992 \\
\hline $\mathrm{H}-\mathrm{CNTs}$ & $2.16 \pm 0.27$ & $<0.0001$ & $0.430 \pm 0.020$ & $<0.0001$ & - & - & 0.983 \\
\hline $\mathrm{C}-\mathrm{CNTs}$ & $1.73 \pm 0.19$ & $<0.0001$ & $0.454 \pm 0.018$ & $<0.0001$ & - & - & 0.989 \\
\hline \multicolumn{8}{|c|}{ Dual-mode model (DMM) } \\
\hline CNTs & $Q^{0}$ & $\mathrm{P}$ of $Q^{0}$ & $b$ & $\mathrm{P}$ of $b$ & $K_{d}$ & P of $K_{d}$ & $r_{a d j}{ }^{2}$ \\
\hline $\mathrm{G}-\mathrm{CNTs}$ & $19.5 \pm 0.8$ & $<0.0001$ & $0.0299 \pm 0.0032$ & $<0.0001$ & $0.020 \pm 0.001$ & $<0.0001$ & 0.998 \\
\hline $\mathrm{H}-\mathrm{CNTs}$ & $22.5 \pm 1.1$ & $<0.0001$ & $0.0237 \pm 0.0030$ & $<0.0001$ & $0.020 \pm 0.001$ & $<0.0001$ & 0.996 \\
\hline $\mathrm{C}-\mathrm{CNTs}$ & $18.9 \pm 1.5$ & $<0.0001$ & $0.0221 \pm 0.0043$ & $<0.0001$ & $0.022 \pm 0.004$ & $<0.0001$ & 0.993 \\
\hline \multicolumn{8}{|c|}{ Polanyi-Manes model (PMM) } \\
\hline CNTs & $Q^{0}$ & $P$ of $Q^{0}$ & $b$ & $P$ of $b$ & $a$ & P of $a$ & $r_{a d j}{ }^{2}$ \\
\hline $\mathrm{G}-\mathrm{CNTs}$ & $44.2 \pm 2.2$ & $<0.0001$ & $1.1704 \pm 0.0977$ & $<0.0001$ & $-10.669 \pm 2.201$ & $<0.0001$ & 0.993 \\
\hline $\mathrm{H}-\mathrm{CNTs}$ & $46.4 \pm 2.6$ & $<0.0001$ & $1.2851 \pm 0.1217$ & $<0.0001$ & $-14.243 \pm 3.807$ & $<0.0001$ & 0.988 \\
\hline $\mathrm{C}-\mathrm{CNTs}$ & $50.5 \pm 4.1$ & $<0.0001$ & $1.0443 \pm 0.1128$ & $<0.0001$ & $-9.130 \pm 2.184$ & $<0.0001$ & 0.989 \\
\hline
\end{tabular}

${ }^{1}$ All estimated parameters values, their standard error, probability of assuming the null hypothesis (P), and the fitting adjusted square of correlation coefficient $\left(r_{a d j}{ }^{2}\right)$ were determined by a commercial software program (Sigmaplot 11.1).

\subsection{Sorption Hysteresis}

In order to further investigate the adsorption mechanism, we conducted continuous desorption experiments after adsorption equilibrium. Figure 1 shows the adsorption-desorption isotherms of nitrobenzene by three different functionalized MWCNTs. Logarithmic transformation on the values of $C_{e}$ and $q_{e}$ was performed for better showing the difference of isotherms at low $C_{e}$ [39]. Sorption hysteresis was generally observed among all three MWCNTs. Desorption hysteresis might be caused by artificial hysteresis, which is caused by insufficient time for equilibrium or some auxiliary process such as degradation, evaporation, etc. $[14,25,26]$. In our study, the equilibrium was reached within 3 days according 
to our preliminary work. MWCNT samples were sealed, mixed in $200 \mathrm{mg} / \mathrm{L}$ sodium azide background solution and kept in black, which could effectively avoid nitrobenzene's evaporation, biological transformation, and photolysis [40]. The $2 \%$ experiment uncertainties further confirmed mass balance calculation. Therefore, the adsorption-desorption hysteresis observed in this study was the true hysteresis, which might be attributed to rearrangement of the bundles or aggregates of MWCNTs [14]. Desorption isotherms clearly shifted to the upper-left direction from the sorption isotherms (Figure 1), indicating that the nitrobenzene molecules tended to remain adsorbed with sorbents during desorption [13].
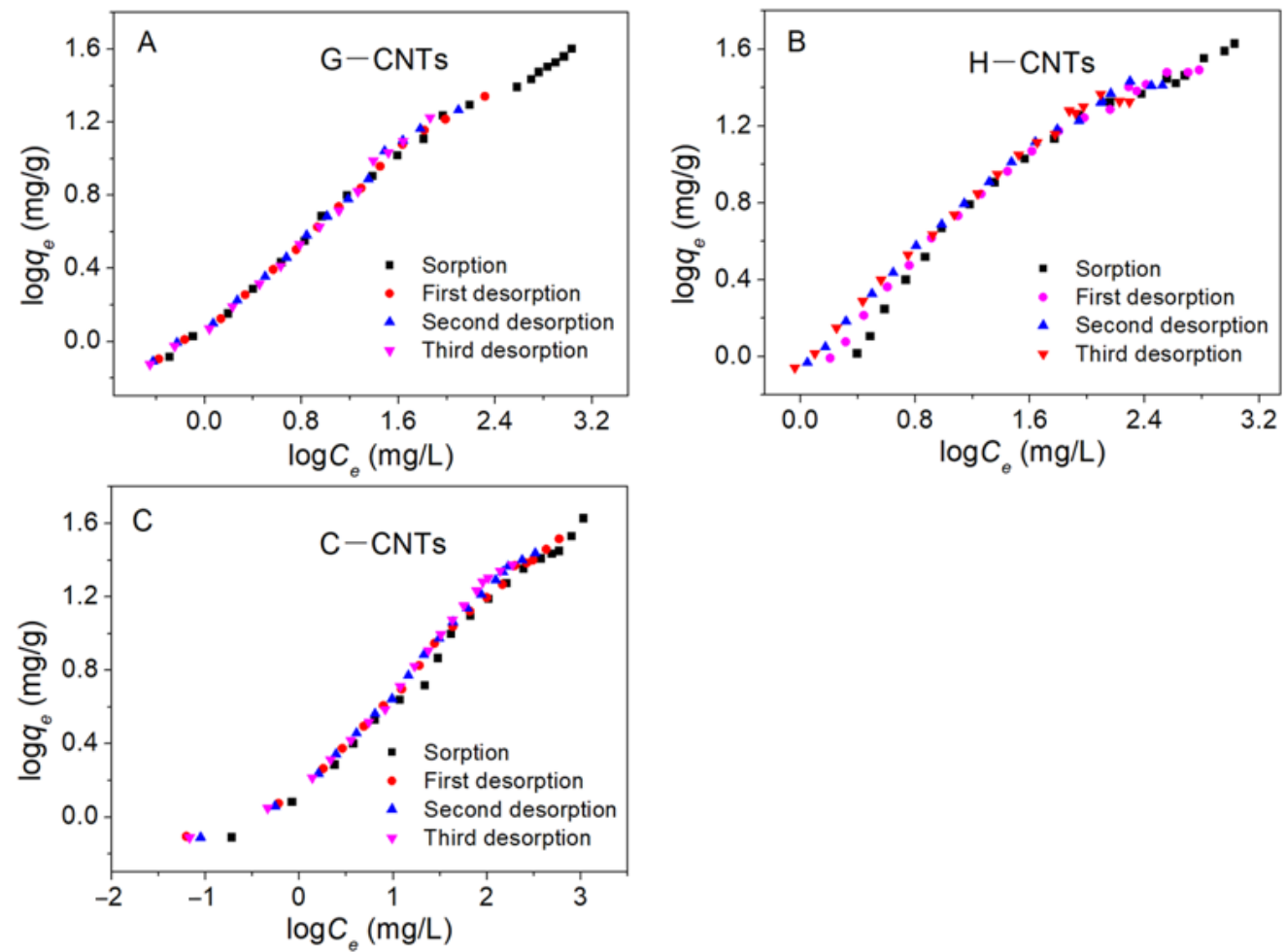

Figure 1. Adsorption-desorption isotherms of nitrobenzene by the three functionalized carbon nanotubes: (A) G-CNTs; (B) H-CNTs; and (C) C-CNTs.

A Freundlich form of TII derived from a wide range of various initial concentration of nitrobenzene was applied to further quantify the adsorption-desorption hysteresis (Figure 2A). Table 2 lists the results of the Freundlich model fit to sorption and desorption data of nitrobenzene by functionalized CNTs, which show that FM model had a good fit for most isotherms. The value of TII of all three MWCNTs varied with the initial concentration of nitrobenzene and could be divided into three stages-at an initial concentration below $40 \mathrm{mg} / \mathrm{L}$, TII decreased with the increasing initial concentration; at an initial concentration between $40 \mathrm{mg} / \mathrm{L}$ to $580 \mathrm{mg} / \mathrm{L}$, TII increased with an increasing initial concentration; and at the initial concentration above $580 \mathrm{mg} / \mathrm{L}$, TII decreased with an increasing initial concentration. TII is the thermodynamic index of irreversibility, the value close to 0 meant that the adsorption-desorption was more reversible, and vice versa. Hence the adsorption-desorption hysteresis of nitrobenzene on MWCNTs experienced five stages (marked on Figure 2A) - more reversible (ab), more irreversible (bc), more reversible (cd), more irreversible (de), and more reversible (ef). At a given initial concentration, the TII value of $\mathrm{H}-\mathrm{CNTs}$ and $\mathrm{C}-\mathrm{CNTs}$ was generally higher than $\mathrm{G}-\mathrm{CNTs}$. This was consistent with the G-CNTs surface functionalization coverage, such that its degree of oxidation was the slightest (Table S1 in Supplementary Materials). This adsorption-desorption phenomenon might affect the stability of MWCNT suspension. 


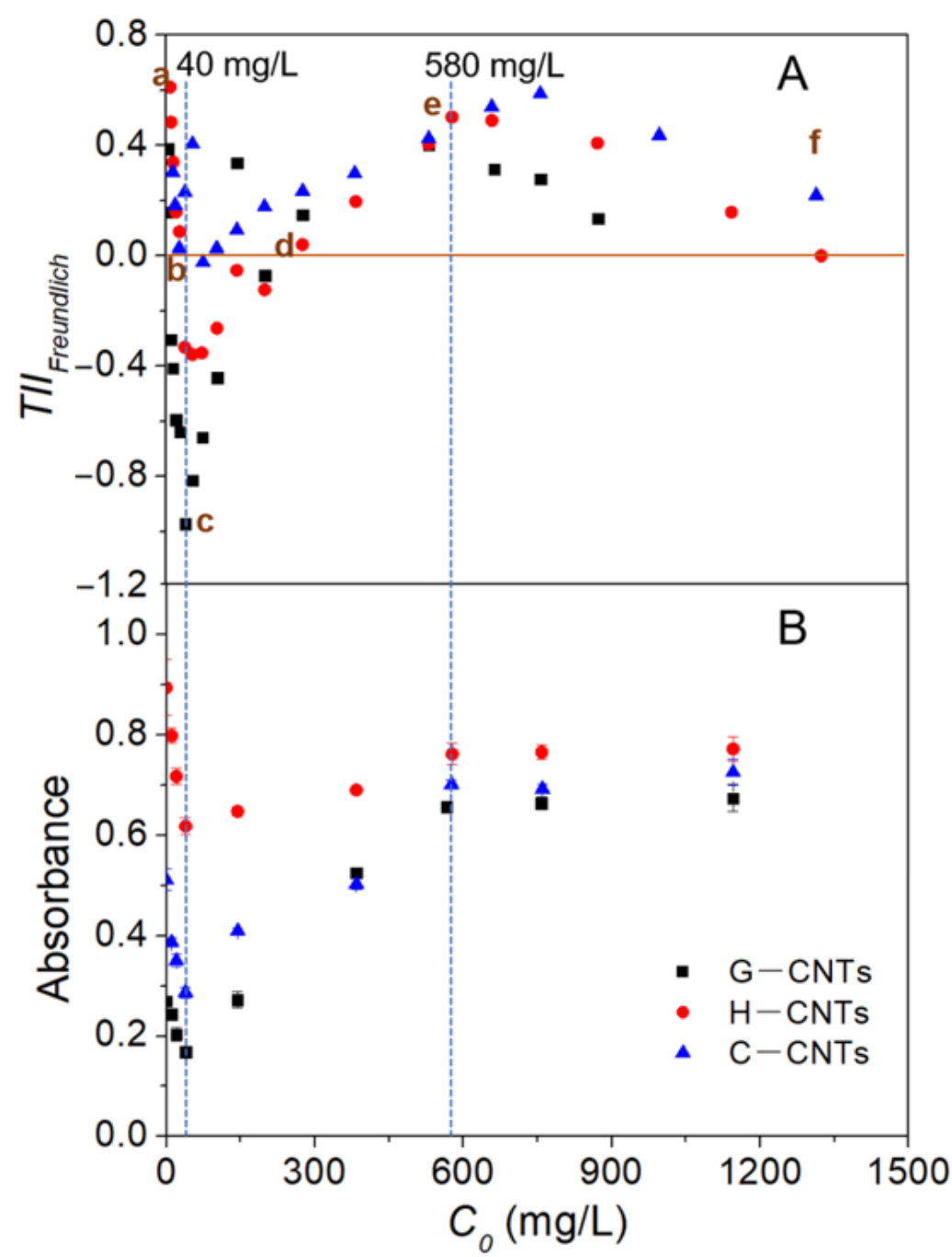

Figure 2. Value of the Freundlich form of TII versus a wide range of initial concentration of nitrobenzene by three functionalized MWCNTs (A); and absorbance at $800 \mathrm{~nm}$ of three functionalized CNTs with a wide range of initial concentration of nitrobenzene after shaking for $72 \mathrm{~h}$ and settling down for $5 \mathrm{~min}$ (B). Error bars represent the standard deviation of three replicates. If error bars are not evident, they are obscured by the points.

\subsection{Stabilization}

Few studies investigated the influence of small dissolved organic molecules on MWCNTs stabilization. As the only dissolved small organic molecule itself without sonication or shaking cannot make a stable MWCNT suspension, similarly, a surfactant by itself is not capable of effectively dispersing MWCNT bundles without vigorous sonication [41]. However, during the process of sorption-desorption, the samples of MWCNTs is under an $150 \mathrm{rpm}$ shaking condition, which facilitates the suspension of MWCNT aggregates. Hence in our study, we selected a 5-min settlement after vigorous shaking to represent the suspension statement during shaking.

Figure S5 (Supplementary Materials) visually shows that the turbidity of MWCNT suspension in all three functionalized MWCNTs varied with initial concentration of nitrobenzene. In a given initial concentration of nitrobenzene, the turbidity of MWCNT of the three functionalized MWCNTs was also different, which might be due to the surface functionalization coverage. 
Table 2. Results of the Freundlich model fits to the sorption and desorption data of nitrobenzene by functionalized CNTs.

\begin{tabular}{|c|c|c|c|c|c|c|c|c|c|c|c|}
\hline \multicolumn{12}{|c|}{ Fitting Parameters under Every $C_{0}(\mathrm{mg} / \mathrm{L})$ by Freundlich Model ${ }^{1}$} \\
\hline \multicolumn{4}{|c|}{ G-CNTs } & \multicolumn{4}{|c|}{$\mathrm{H}-\mathrm{CNTs}$} & \multicolumn{4}{|c|}{$\mathrm{C}-\mathrm{CNTs}$} \\
\hline$C_{0}$ & $K_{f}$ & $n$ & $r_{a d j}^{2}$ & $C_{0}$ & $K_{f}$ & $n$ & $r_{a d j}^{2}$ & $C_{0}$ & $K_{f}$ & $n$ & $r_{a d j}{ }^{2}$ \\
\hline 5.68 & $0.987 \pm 0.046$ & $0.253 \pm 0.053$ & 0.919 & 8.98 & $0.902 \pm 0.010$ & $0.167 \pm 0.020$ & 0.973 & 5.06 & $1.258 \pm 0.022$ & $0.144 \pm 0.032$ & 0.912 \\
\hline 7.48 & $1.163 \pm 0.027$ & $0.347 \pm 0.054$ & 0.953 & 11.06 & $1.008 \pm 0.022$ & $0.221 \pm 0.029$ & 0.966 & 14.48 & $1.493 \pm 0.042$ & $316 \pm 0.046$ & 959 \\
\hline 10.47 & $1.130 \pm 0.018$ & $0.538 \pm 0.052$ & 0.982 & 14.93 & $1.220 \pm 0.039$ & $0.284 \pm 0.032$ & 0.976 & 19.54 & $1.570 \pm 0.078$ & $0.370 \pm 0.047$ & 0.969 \\
\hline 14.66 & $1.152 \pm 0.038$ & $0.581 \pm 0.044$ & 0.983 & 21.13 & $1.380 \pm 0.068$ & $0.361 \pm 0.035$ & 0.981 & 27.57 & $1.527 \pm 0.115$ & $0.441 \pm 0.047$ & 0.977 \\
\hline 21.30 & $1.049 \pm 0.041$ & $0.658 \pm 0.031$ & 0.996 & 28.06 & $1.513 \pm 0.035$ & $0.392 \pm 0.014$ & 0.998 & 39.08 & $1.888 \pm 0.296$ & $0.349 \pm 0.074$ & 0.915 \\
\hline 28.98 & $0.987 \pm 0.083$ & $0.676 \pm 0.049$ & 0.990 & 38.83 & $1.275 \pm 0.163$ & $0.572 \pm 0.062$ & 0.977 & 54.18 & $2.352 \pm 0.585$ & $0.269 \pm 0.096$ & 0.795 \\
\hline 39.68 & $0.774 \pm 0.227$ & $0.814 \pm 0.141$ & 0.945 & 54.01 & $1.265 \pm 0.174$ & $0.583 \pm 0.055$ & 0.982 & 75.65 & $1.734 \pm 1.187$ & $0.464 \pm 0.215$ & 0.742 \\
\hline 54.37 & $0.829 \pm 0.128$ & $0.749 \pm 0.061$ & 0.987 & 73.34 & $1.326 \pm 0.166$ & $0.581 \pm 0.044$ & 0.989 & 103.5 & $1.975 \pm 0.353$ & $0.441 \pm 0.053$ & 0.971 \\
\hline 74.82 & $0.912 \pm 0.095$ & $0.685 \pm 0.035$ & 0.995 & 103.7 & $1.533 \pm 0.179$ & $0.542 \pm 0.035$ & 0.992 & 144.3 & $2.266 \pm 0.311$ & $0.411 \pm 0.036$ & 0.985 \\
\hline 104.4 & $1.206 \pm 0.260$ & $0.595 \pm 0.064$ & 0.977 & 143.8 & $2.177 \pm 0.239$ & $0.452 \pm 0.029$ & 0.992 & 199.9 & $2.772 \pm 0.269$ & $0.373 \pm 0.017$ & 0.992 \\
\hline 144.5 & $4.197 \pm 0.732$ & $0.274 \pm 0.047$ & 0.945 & 200.3 & $2.077 \pm 0.285$ & $0.483 \pm 0.033$ & 0.991 & 277.1 & $3.236 \pm 0.258$ & $0.347 \pm 0.017$ & 0.995 \\
\hline 200.8 & $2.323 \pm 0.342$ & $0.442 \pm 0.035$ & 0.987 & 384.2 & $3.537 \pm 0.306$ & $0.345 \pm 0.017$ & 0.995 & 381.9 & $3.906 \pm 0.428$ & $0.318 \pm 0.022$ & 0.991 \\
\hline 276.8 & $3.356 \pm 0.395$ & $0.352 \pm 0.026$ & 0.989 & 531.6 & $6.334 \pm 1.149$ & $0.255 \pm 0.034$ & 0.965 & 531.6 & $5.631 \pm 1.096$ & $0.261 \pm 0.037$ & 0.963 \\
\hline 531.6 & $5.792 \pm 0.656$ & $0.246 \pm 0.021$ & 0.985 & 578.6 & $7.483 \pm 1.134$ & $0.213 \pm 0.028$ & 0.966 & 658.7 & $7.555 \pm 0.345$ & $0.209 \pm 0.008$ & 0.997 \\
\hline 664.3 & $4.736 \pm 0.212$ & $0.283 \pm 0.008$ & 0.999 & 659.2 & $7.663 \pm 1.003$ & $0.219 \pm 0.024$ & 0.977 & 757.0 & $8.640 \pm 0.913$ & $0.187 \pm 0.019$ & 0.981 \\
\hline 757.9 & $4.490 \pm 1.420$ & $0.298 \pm 0.053$ & 0.968 & 872.2 & $6.899 \pm 0.753$ & $0.254 \pm 0.019$ & 0.989 & 997.3 & $6.217 \pm 0.331$ & $0.255 \pm 0.009$ & 0.998 \\
\hline 873.5 & $0.357 \pm 0.056$ & $0.357 \pm 0.056$ & 0.975 & 1143.1 & $3.305 \pm 0.547$ & $0.362 \pm 0.026$ & 0.990 & 1314.1 & $3.573 \pm 0.736$ & $0.354 \pm 0.032$ & 0.984 \\
\hline - & - & - & - & 1324.5 & $2.105 \pm 0.604$ & $0.430 \pm 0.044$ & 0.980 & - & - & - & - \\
\hline
\end{tabular}

${ }^{1}$ All estimated parameters values, their standard error, and the fitting adjusted square of correlation coefficient $\left(r_{a d j}{ }^{2}\right)$ were determined by a commercial software program (Origin 8.5).

The turbidity of MWCNT suspension with different initial concentration of nitrobenzene after 5-min settlement was further examined using the absorbance at $800 \mathrm{~nm}$ (Figure 2B). Similar to TII, the value of absorbance at $800 \mathrm{~nm}$ of all three MWCNTs varied with initial concentration of nitrobenzene and could be divided into three stages-at an initial concentration below $40 \mathrm{mg} / \mathrm{L}$, the value of absorbance decreased with the increasing initial concentration; at an initial concentration between $40 \mathrm{mg} / \mathrm{L}$ to $580 \mathrm{mg} / \mathrm{L}$, absorbance increased with the increasing initial concentration; at the initial concentration above $580 \mathrm{mg} / \mathrm{L}$, the absorbance reached a plateau. The maximum turbidity above $580 \mathrm{mg} / \mathrm{L}$ was about 3 times the minimum turbidity at $40 \mathrm{mg} / \mathrm{L}$. The similar tendency of TII and turbidity indicated that sorption hysteresis was highly related with the stability of MWCNTs suspension. Turbidity is the cloudiness or haziness of a fluid caused by individual particles (suspended solids). The higher the turbidity, the smaller the particles that remain in solution, which could increase the surface area of MWCNTs and consequently be expected to enhance the nitrobenzene adsorption [10,42].

The smaller size CNTs with good stability were easier to diffuse, migrate, transport, and uptake by plankton $[9,43]$. Except phagocytosis and macropinocytosis, CNTs with a small size can also enter the cell through receptor-mediated endocytosis [43], which can generate intracellular reactive oxygen species (ROS) under minor damage to cell membrane integrity [44]. As the smaller size CNTs have more electron donor or acceptor active sites with molecular dioxygen [45], they could generate more ROS and increase their toxicity [46].

At a given initial concentration, Turbidity of $\mathrm{H}-\mathrm{CNTs}$ and $\mathrm{C}-\mathrm{CNTs}$ are generally higher than $\mathrm{G}-\mathrm{CNTs}$. This is related to their higher degree of oxidation and resulting hydrophilicity on the surface (Table S1 in Supplementary Materials). As the toxicity of $\mathrm{H}-\mathrm{CNTs}$ and $\mathrm{C}-\mathrm{CNTs}$ increase significantly, leading to more proliferation inhibition and cell death [47], more attention should be paid to the health risk of such CNTs in the water environment.

\subsection{Possible Adsorption-Desorption Mechanisms of Nitrobenzene on MWCNTs}

The adsorption-desorption results of nitrobenzene (as discussed above) showed that adsorption-desorption hysteresis was relevant to the stability of MWCNTs suspension, which was affected by the initial concentration of nitrobenzene and the surface functionalization coverage of MWCNTs. A conceptual adsorption-desorption model was proposed 
to further explain the relationship among the sorption hysteresis, stability of MWCNTs suspension, and the initial concentration of nitrobenzene (Figure 3). There are mainly three areas for nitrobenzene sorption on MWCNTs—surface, groove, and interstitial spaces (Figure 3) [14]. At a very low initial concentration of nitrobenzene (Figure 3a), the stability of MWCNT suspension was mainly dependent on MWCNTs' own surface properties. The relatively higher surface functionalization coverage of $\mathrm{H}-\mathrm{CNT}$ makes it more hydrophilic, which results in a higher area of interstitial spaces, and thus, higher irreversibility of sorption hysteresis. With an increase in the initial concentration of nitrobenzene (Figure 3b), the small amount of nitrobenzene created a nonpolar environment for MWCNTs [17], which resulted in a low turbidity of the MWCNT suspension. At this step, the interstitial spaces were compressed by nitrobenzene and it was more difficult for the nitrobenzene molecular to penetrate through, which then cause more reversible adsorption-desorption process. As the initial concentration of nitrobenzene continued increasing (Figure 3c), the nonpolar environment further induced the aggregation of MWCNTs, which led to the formation of new interstitial spaces. The sorbed nitrobenzene molecule might have been trapped into the newly formed interstitial spaces resulting in a more irreversible adsorption-desorption process. As more and more nitrobenzene molecules were sorbed onto MWCNTs (Figure 3d), the nitro group made the MWCNT surface more hydrophilic, which facilitated the suspension of MWCNTs. In this range of concentration, no new interstitial spaces could form and the existent interstitial spaces were more difficult for the nitrobenzene to penetrate into, and thus, it result in a more reversible adsorption-desorption process. With the initial concentration of nitrobenzene further increasing (Figure 3e), more and more nitro group on the surface of MWCNTs enlarged the area of interstitial spaces, which helped nitrobenzene to penetrate. Hence, the adsorption-desorption became more irreversible. When the turbidity of CNTs suspension reached a plateau (Figure 3f), there was no more area for the nitrobenzene to sorb onto CNTs. However, the adsorption amount of nitrobenzene still increased linearly with the nitrobenzene equilibrium concentration (Figure S1 in Supplementary Materials). This might be attributed to the bilayer sorption between the sorbed nitrobenzene and free nitrobenzene, which would increase the proportion of reversible sorption, and therefore, result in a more reversible sorption-desorption process. Thus, the DMM model was fitter than the PMM model for nitrobenzene's sorption onto CNTs.

a
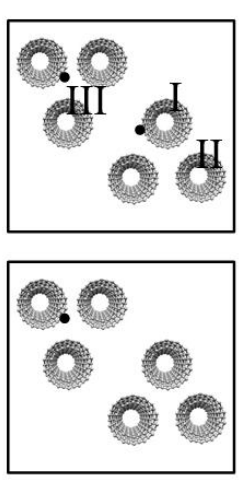

Low b

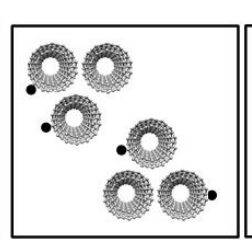

$\mathrm{c}$
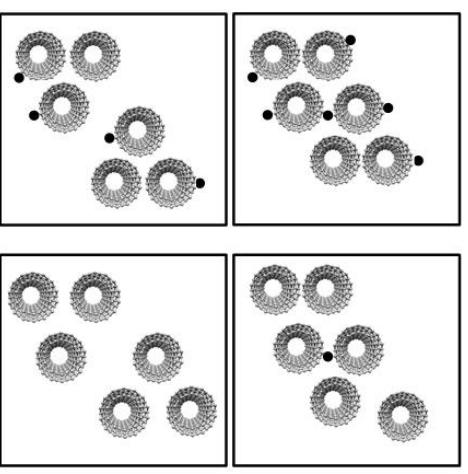

d
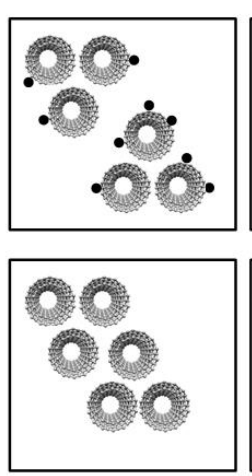

e
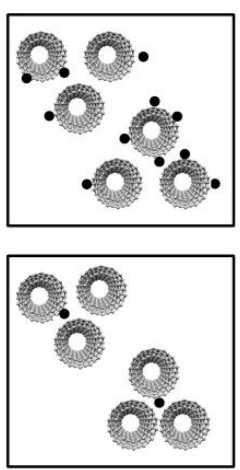

f
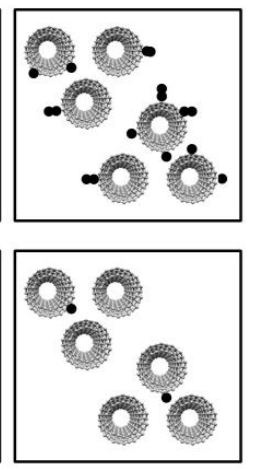

High

Figure 3. Schematic diagrams for the adsorption-desorption of nitrobenzene on CNTs. The letters I, II, and III indicate the possible adsorption area of the surface, groove, and interstitial spaces, respectively. The lowercase letters " $a, b, c$, d, e, $\mathrm{f}^{\prime \prime}$ represent the beginning or end of five stages of adsorption-desorption hysteresis of nitrobenzene on MWCNTs: more reversible $(\mathbf{a}, \mathbf{b})$ - more irreversible $(\mathbf{b}, \mathbf{c})$-more reversible $(\mathbf{c}, \mathbf{d})$-more irreversible $(\mathbf{d}, \mathbf{e})$-more reversible $(\mathbf{e}, \mathbf{f})$. $C_{0}$ is the initial concentration of nitrobenzene. 
Nitrobenzene might be adsorbed first onto MWCNTs with aromatic rings binding to the surface carbon rings via $\pi-\pi$ interactions, hydrophobic interactions or with nitro group binding to the functional group on MWCNT surface to form a monolayer, the nitrobenzene monolayer then further sorbed the dissolved nitrobenzene by hydrogen bonds and other polar interactions. Differences of interaction force between nitrobenzene and CNTs under different initial concentrations of nitrobenzene, not only affected the stability of CNTs but also affected the release, persistence, and bioavailability of the adsorbed nitrobenzene $[6,47,48]$. It is advised that the intake for nitrobenzene should not reach $17 \mu \mathrm{g} / \mathrm{L}$, for human safety [33].

\section{Conclusions}

The stability of CNTs suspension is a key factor in determining their behavior, transport, bioavailability, and toxicity in the aquatic environment. Our experiments demonstrated that the adsorption of nitrobenzene can affect CNTs' stability. A conceptual adsorption-desorption model was proposed to explain the possible mechanism of the different stability of MWCNTs suspension under different initial concentrations of nitrobenzene. This study also found that the stability of CNTs containing carboxyl groups and hydroxyl groups were more sensitive to nitrobenzene concentrations than G-CNTs. Therefore, the structure and types of carbon nanotubes should be considered when selecting CNTs as adsorbents for wastewater treatment, or evaluating the risk of CNTs in natural water.

Additionally, the experimental phenomena that the dissolved nitrobenzene molecular and the functionalized surface could affect the stability of MWCNTs aggregation raises a question about the efficient contact area that nitrobenzene molecules can attach to. Based on the maximum monolayer adsorption capacity of the DMM model, we calculated the efficient maximum contact area according to following equation:

$$
\begin{gathered}
A_{\text {surf }}=Q_{m} \times\left(A_{m} \times N\right) / 10^{10} \\
A_{m}=\pi \times(3 \mathrm{MW} /(4 \pi \times D \times N))^{2 / 3}
\end{gathered}
$$

where $A_{\text {surf }}$ is the CNT surface area $\left(\mathrm{m}^{2} / \mathrm{g}\right) ; A_{m}$ is the projecting area of a single adsorbate molecule $\left(\mathrm{cm}^{2}\right) ; \mathrm{N}$ is the Avogadro constant, and MW is the molecular weight $(\mathrm{g} / \mathrm{mol})$. The calculated area for G-CNTs, H-CNTs, and C-CNTs were $30.9 \mathrm{~m}^{2}, 39.5 \mathrm{~m}^{2}$, and $35.0 \mathrm{~m}^{2}$, respectively. This was much smaller than the special surface area measured by $\mathrm{N}_{2}$ adsorption and was more reasonable. As CNTs aggregated in nitrobenzene solutions that inhibited the nitrobenzene from reaching the adsorption sites inside the CNTs aggregates, it could be used as a reference for the evaluation of the adsorption effect of CNTs on nitrobenzene, in wastewater treatment.

The methodology that combined the adsorption isotherm, adsorption-desorption hysteresis index and the stability of CNTs, provides a new direction to study the sorptiondesorption mechanisms of organic compounds on CNTs, in wastewater treatment or ecological risk assessment of pollutants. Further studies should compare the effect of different polar organic compounds on the stability of CNTs aggregation, and quantify the ecotoxicological effects of CNTs after adsorption of different amounts of nitrobenzene.

Supplementary Materials: The following are available online at https: / www.mdpi.com/article / 10.3390/w13101426/s1. Figure S1: The chemical structure sketches of three functionalized carbon nanotubes-(A) multiwalled structure of three carbon nanotubes; (B) the surface of G-CNTs; (C) the surface of $\mathrm{H}-\mathrm{CNTs}$; and (D) the surface of $\mathrm{C}-\mathrm{CNTs}$. Table S1: Selected physicochemical properties of CNTs. Figure S2. The nitrogen adsorption-desorption isotherms that were obtained using a surface area and porosimetry analyzer (ASAP 2460, Micromeritics, USA)—(A) G-CNTs; (B) G-CNTs; and (C) G-CNTs. Figure S3: Sorption isotherms of nitrobenzene by three functionalized carbon nanotubes-(A) G-CNTs; (B) H-CNTs; and (C) C-CNTs. Figure S4: Photo of three functionalized MWCNT suspension with different initial concentrations of nitrobenzene, after $72 \mathrm{~h}$ shaking and 
$1 \mathrm{~h}$ settlement. Figure S5: Photo of three functionalized MWCNT suspensions with different initial concentration of nitrobenzene, after $72 \mathrm{~h}$ of shaking and 5 minutes of settlement.

Author Contributions: Conceptualization, Z.J. and D.L.; methodology, Z.J.; software, Z.J.; validation, Z.J. and D.L.; formal analysis, Z.J.; investigation, Z.J.; writing-original draft preparation, Z.J.; writing-review and editing, D.L. All authors have read and agreed to the published version of the manuscript.

Funding: This research was funded by "Shenyang Pioneer Scientific and Technological Innovation Talents Team, grant number RC190362", "Revitalize Liaoning Talents Program, grant number XLYC1907136 and XLYC1907118”, "Liaoning Province Natural Science Foundation, grant number 2020-YQ-10" and "CAS Pioneer Hundred Talents Program awarded to X.-J.Z. (2016-2021)".

Institutional Review Board Statement: Not applicable.

Informed Consent Statement: Not applicable.

Data Availability Statement: The data used to support the conclusions of this article are available from the corresponding author upon request.

Acknowledgments: This research is part of the Environmental Micro-Interfacial Chemistry Group. Sincere thanks to the Institute of Applied Ecology for the excellent support and scientific management services.

Conflicts of Interest: The authors declare no conflict of interest.

\section{References}

1. Iijima, S. Helical microtubules of graphitic carbon. Nature 1991, 354, 56-58. [CrossRef]

2. Simon, P.; Gogotsi, Y. Materials for electrochemical capacitors. Nat. Mater. 2008, 7, 845-854. [CrossRef]

3. De Volder, M.F.L.; Tawfick, S.H.; Baughman, R.H.; Hart, A.J. Carbon nanotubes: Present and future commercial applications. Science 2013, 339, 535-539. [CrossRef]

4. Humoud, M.S.; Roy, S.; Mitra, S. Scaling reduction in carbon nanotube-immobilized membrane during membrane distillation. Water 2019, 11, 2588. [CrossRef]

5. Kukkar, D.; Rani, A.; Kumar, V.; Younis, S.A.; Zhang, M.; Lee, S.S.; Tsang, D.C.W.; Kim, K.H. Recent advances in carbon nanotube sponge-based sorption technologies for mitigation of marine oil spills. J. Colloid Interf. Sci. 2020, 570, 411-422. [CrossRef] [PubMed]

6. Ahmad, J.; Naeem, S.; Ahmad, M.; Usman, A.R.A.; Al-Wabel, M.I. A critical review on organic micropollutants contamination in wastewater and removal through carbon nanotubes. J. Environ. Manag. 2019, 246, 214-228. [CrossRef]

7. Zhao, J.; Luo, W.; Xu, Y.; Ling, J.; Deng, L. Potential reproductive toxicity of multi-walled carbon nanotubes and their chronic exposure effects on the growth and development of Xenopus tropicalis. Sci. Total Environ. 2021, 766, 142652. [CrossRef] [PubMed]

8. Lin, D.; Xing, B. Phytotoxicity of nanoparticles: Inhibition of seed germination and root growth. Environ. Pollut. 2007, 150, 243-250. [CrossRef] [PubMed]

9. Klaine, S.J.; Alvarez, P.J.J.; Batley, G.E.; Fernandes, T.F.; Handy, R.D.; Lyon, D.Y.; Mahendra, S.; McLaughlin, M.J.; Lead, J.R. Nanomaterials in the environment: Behavior, fate, bioavailability, and effects. Environ. Toxicol. Chem. 2008, 27, $1825-1851$. [CrossRef]

10. Glomstad, B.; Zindler, F.; Jenssen, B.M.; Booth, A.M. Dispersibility and dispersion stability of carbon nanotubes in synthetic aquatic growth media and natural freshwater. Chemosphere 2018, 201, 269-277. [CrossRef] [PubMed]

11. Yang, K.; Xing, B.S. Adsorption of organic compounds by carbon nanomaterial in aqueous phase: Polanyi theory and its application. Chem. Rev. 2010, 110, 5989-6008. [CrossRef] [PubMed]

12. Yang, K.; Zhu, L.Z.; Xing, B.S. Adsorption of polycyclic aromatic hydrocarbons by carbon nanomaterials. Environ. Sci. Technol. 2006, 40, 1855-1861. [CrossRef] [PubMed]

13. Wang, Z.Y.; Yu, X.D.; Pan, B.; Xing, B.S. Norfloxacin sorption and its thermodynamics on surface-modified carbon nanotubes. Environ. Sci. Technol. 2010, 44, 978-984. [CrossRef] [PubMed]

14. Pan, B.; Lin, D.H.; Mashayekhi, H.; Xing, B.S. Adsorption and hysteresis of bisphenol A and $17 \alpha$-ethinyl estradiol on carbon nano-materials. Environ. Sci. Technol. 2008, 42, 5480-5485. [CrossRef] [PubMed]

15. Smith, B.; Yang, J.; Bitter, J.L.; Ball, W.P.; Fairbrother, D.H. Influence of Surface Oxygen on the interactions of carbon nanotubes with natural organic matter. Environ. Sci. Technol. 2012, 46, 12839-12847. [CrossRef]

16. Li, Y.H.; Wang, S.G.; Wei, J.Q.; Zhang, X.F.; Xu, C.L.; Luan, Z.K.; Wu, D.H.; Wei, B.Q. Lead adsorption on carbon nanotubes. Chem. Phys. Lett. 2002, 357, 263-266. [CrossRef]

17. Zhao, X.C.; Liu, R.T.; Chi, Z.X.; Teng, Y.; Qin, P.F. New insights into the behavior of bovine serum albumin adsorption adsorbed onto carbon nanotubes: Comprehensive spectroscopic studies. J. Phys. Chem. B 2010, 114, 5625-5631. [CrossRef] 
18. Pignatello, J.J.; Xing, B.S. Mechanisms of slow sorption of organic chemicals to natural particles. Environ. Sci. Technol. 1996, 30, 1-11. [CrossRef]

19. Sander, M.; Pignatello, J.J. On the reversibility of sorption to black carbon: Distinguishing true hysteresis from artificial hysteresis caused by dilution of a competing adsorbate. Environ. Sci. Technol. 2007, 41, 843-849. [CrossRef]

20. Sander, M.; Pignatello, J.J. Sorption irreversibility of 1,4-dichlorobenzene in two natural organic matter-rich geosorbents. Environ. Toxicol. Chem. 2009, 28, 447-457. [CrossRef]

21. Huang, W.L.; Yu, H.; Weber, W.J. Hysteresis in the sorption and desorption of hydrophobic organic contaminants by soils and sediments: 1. A comparative analysis of experimental protocols. J. Contam. Hydrol. 1998, 31, 129-148. [CrossRef]

22. Weber, W.J.; Huang, W.L.; Yu, H. Hysteresis in the sorption and desorption of hydrophobic organic contaminants by soils and sediments: 2. Effects of soil organic matter heterogeneity. J. Contam. Hydrol. 1998, 31, 149-165. [CrossRef]

23. Lu, Y.F.; Pignatello, J.J. History-dependent sorption in humic acids and a lignite in the context of a polymer model for natural organic matter. Environ. Sci. Technol. 2004, 38, 5853-5862. [CrossRef]

24. Lu, Y.F.; Pignatello, J.J. Sorption of apolar aromatic compounds to soil humic acid particles affected by aluminum(III) ion crosslinking. J. Environ. Qual. 2004, 33, 1314-1321. [CrossRef] [PubMed]

25. Sander, M.; Lu, Y.F.; Pignatello, J.J. A thermodynamically based method to quantify true sorption hysteresis. J. Environ. Qual. 2005, 34, 1063-1072. [CrossRef] [PubMed]

26. Lu, Y.F.; Pignatello, J.J. Demonstration of the "conditioning effect" in soil organic matter in support of a pore deformation mechanism for sorption hysteresis. Environ. Sci. Technol. 2002, 36, 4553-4561. [CrossRef] [PubMed]

27. Yang, K.; Xing, B.S. Desorption of polycyclic aromatic hydrocarbons from carbon nanomaterials in water. Environ. Pollut. 2007, 145, 529-537. [CrossRef]

28. Zhao, J.J.; Buldum, A.; Han, J.; Lu, J.P. Gas molecule adsorption in carbon nanotubes and nanotube bundles. Nanotechnology 2002, 13, 195-200. [CrossRef]

29. Deline, A.R.; Frank, B.P.; Smith, C.L.; Sigmon, L.R.; Wallace, A.N.; Gallagher, M.J.; Goodwin, D.G., Jr.; Durkin, D.P.; Fairbrother, D.H. Influence of oxygen-containing functional groups on the environmental properties, transformations, and toxicity of carbon nanotubes. Chem. Rev. 2020, 120, 11651-11697. [CrossRef]

30. Cho, H.H.; Smith, B.A.; Wnuk, J.D.; Fairbrother, D.H.; Ball, W.P. Influence of surface oxides on the adsorption of naphthalene onto multiwalled carbon nanotubes. Environ. Sci. Technol. 2008, 42, 2899-2905. [CrossRef]

31. Hevia, L.G.; Fanarraga, M.L. Microtubule cytoskeleton-disrupting activity of MWCNTs: Applications in cancer treatment. J. Nanobiotechnol. 2020, 18, 11. [CrossRef]

32. Fan, B.; Wang, X.; Xie, Z.; Li, J.; Gao, X.; Cui, L.; Gao, S.; Liu, Z. Aquatic life criteria \& human health ambient water quality criteria derivations and probabilistic risk assessments of 7 benzenes in China. Chemosphere 2021, 274, 129784.

33. Nematollahzadeh, A.; Babapoor, A.; Mousavi, S.M.; Nuri, A. Nitrobenzene adsorption from aqueous solution onto polythiophenemodified magnetite nanoparticles. Mater. Chem. Phys. 2021, 262, 124266. [CrossRef]

34. Zhang, D.; Pan, B.; Zhang, H.; Ning, P.; Xing, B. Contribution of Different Sulfamethoxazole Species to Their Overall Adsorption on Functionalized Carbon Nanotubes. Environ. Sci. Technol. 2010, 44, 3806-3811. [CrossRef]

35. Li, H.; Zhang, D.; Han, X.; Xing, B. Adsorption of antibiotic ciprofloxacin on carbon nanotubes: $\mathrm{pH}$ dependence and thermodynamics. Chemosphere 2014, 95, 150-155. [CrossRef]

36. Lin, D.H.; Xing, B.S. Tannic acid adsorption and its role for stabilizing carbon nanotube suspensions. Environ. Sci. Technol. 2008, 42, 5917-5923. [CrossRef]

37. Lin, D.H.; Liu, N.; Yang, K.; Xing, B.S.; Wu, F.C. Different stabilities of multiwalled carbon nanotubes in fresh surface water samples. Environ. Pollut. 2010, 158, 1270-1274. [CrossRef]

38. Xing, B.S.; Pignatello, J.J. Dual-mode sorption of low-polarity compounds in glassy poly(vinyl chloride) and soil organic matter. Environ. Sci. Technol. 1997, 31, 792-799. [CrossRef]

39. Pan, B.; Zhang, D.; Li, H.; Wu, M.; Wang, Z.Y.; Xing, B.S. Increased adsorption of sulfamethoxazole on suspended carbon nanotubes by dissolved humic acid. Environ. Sci. Technol. 2013, 47, 7722-7728. [CrossRef]

40. Zhao, Q.; Li, P.J.; Stagnitti, F.; Ye, J.; Dong, D.B.; Zhang, Y.Q.; Li, P. Effects of aging and freeze-thawing on extractability of pyrene in soil. Chemosphere 2009, 76, 447-452. [CrossRef]

41. Matarredona, Q.; Rhoads, H.; Li, Z.R.; Harwell, J.H.; Balzano, L.; Resasco, D.E. Dispersion of single-walled carbon nanotubes in aqueous solutions of the anionic surfactant NaDDBS. J. Phys. Chem. B 2003, 107, 13357-13367. [CrossRef]

42. Liu, C.H.; Li, J.J.; Zhang, H.L. Structure dependent interaction between organic dys and carbon nanotubes. Colloid Surface A 2008, 313-314, 9-12. [CrossRef]

43. Kettler, K.; Veltman, K.; van de Meent, D.; van Wezel, A.; Hendriks, A.J. Cellular uptake of nanoparticles as determined by particle properties, experimental conditions, and cell type. Environ. Toxicol. Chem. 2014, 33, 481-492. [CrossRef] [PubMed]

44. Zhang, X.J.; Zhang, Z.M.; Zhang, S.Y.; Xing, W.W.; Wang, J.; Li, H.B.; Zhao, Q.; Xing, B.S. Size effect on the cytotoxicity of layered black phosphorus and underlying mechanisms. Small 2017, 13, 701-709. [CrossRef] [PubMed]

45. Nel, A.; Xia, T.; Madler, L.; Li, N. Toxic potential of materials at the nanolevel. Science 2006, 311, 622-627. [CrossRef] [PubMed]

46. Azari, M.R.; Mohammadian, Y. Comparing in vitro cytotoxicity of graphite, short multi-walled carbon nanotubes, and long multi-walled carbon nanotubes. Environ. Sci. Pollut. Res. 2020, 27, 15401-15406. [CrossRef] 
47. Magrez, A.; Kasas, S.; Salicio, V.; Pasquier, N.; Seo, J.W.; Celio, M.; Catsicas, S.; Schwaller, B.; Forro, L. Cellular toxicity of carbon-based nanomaterials. Nano Lett. 2006, 6, 1121-1125. [CrossRef]

48. Zhao, Q.; Yang, K.; Zhang, S.Y.; Chefetz, B.; Zhao, J.; Mashayekhi, H.; Xing, B.S. Dispersant selection for nanomaterials: Insight into dispersing functionalized carbon nanotubes by small polar aromatic organic molecules. Carbon 2015, 91, 494-505. [CrossRef] 